\title{
Pirólise de Resíduos Poliméricos Gerados por Atividades Offshore
}

\author{
Mara L. de Oliveira, Lucianna L. Cabral, Marcia C. A. M. Leite, Mônica R. C. Marques \\ Laboratório de Tecnologia Ambiental, Instituto de Química, UERJ
}

\begin{abstract}
Resumo: Resíduos plásticos gerados pelas atividades offshore da indústria de exploração e produção de óleo e gás, após caracterização por ensaio de identificação das classes poliméricas e análise térmica, foram pirolisados em atmosfera inerte a $450{ }^{\circ} \mathrm{C}$. Os óleos pirolíticos foram caracterizados por espectrofotometria de infravermelho por transformada de Fourier (FTIR) e cromatografia em fase gasosa acoplada à espectrometria de massas (CG/EM), indicando a composição de parafinas, olefinas e aromáticos.
\end{abstract}

Palavras-chave: Pirólise, resíduo offshore, caracterização de polímeros.

\section{Pyrolysis of Offshore Solid Wastes}

Abstract: Solid wastes from oil and gas offshore exploration and production activities, after characterization of polymeric classes and thermal identification analysis tests, were pyrolysed under an inert atmosphere at $450{ }^{\circ} \mathrm{C}$. The pyrolysis oil was characterized by Fourier Transform Infrared Spectroscopy (FTIR) gas chromatography mass spectrometry (CG/EM), indicating high generation of paraffin, olefines and aromatics.

Keywords: Pyrolysis, waste offshore, polymers characterization.

\section{Introdução}

A exploração e a produção (E\&P) de petróleo e gás em ambiente marítimo são atividades que vêm se desenvolvendo tecnologicamente visando à exploração de reservas em águas profundas e ultra profundas. São consideradas de extrema importância, porque a matriz energética mundial depende, em grande parte, destas reservas. Entretanto, estas atividades são potencialmente causadoras de impactos ambientais, principalmente devido à natureza de seus resíduos que necessitam de tratamento específico para possibilitar a disposição final no meio ambiente de forma segura $^{[1]}$.

Com o desenvolvimento crescente das atividades de E\&P, seus impactos ambientais têm sido amplamente discutidos com o objetivo de avaliar sua magnitude, bem como evitá-los ou minimizá-los. Para sua mitigação, faz-se necessária a implantação de tecnologias que possibilitem a disposição final dos resíduos no meio ambiente de forma segura $^{[2]}$.

A Tabela 1 apresenta os principais tipos de resíduos gerados nas unidades marítimas da Petrobras que operam na Bacia de Campos, sua respectiva classificação segundo a NBR $10.004^{[3]}$ e a forma usual de destinação final empregada por esta empresa.

Observa-se que a incineração é a forma de disposição final mais utilizada para a extinção de resíduos classificados como perigosos (classe I). Entretanto, essa forma de disposição, mesmo que adequada e de acordo com as diretrizes estabelecidas na legislação ambiental, apresenta um impacto ambiental considerável em função das emissões de gases de efeito estufa.

Além da diversidade dos resíduos gerados por esta atividade, a quantidade extremamente elevada é um outro fator que contribui significativamente para a potencialidade de seus impactos. Oliveira $(2006)^{[5]}$ cita que a Petrobras gerou no período de janeiro a julho de 2005, cerca de 20 mil toneladas de resíduos offshore. Dentre estes resíduos, cerca de $20 \%$ correspondem a resíduos com potencial energético, que são constituídos de polímeros orgânicos, naturais ou sintéticos, ou de materiais de base orgânica e que poderiam ser reaproveitados transformando-se em insumo energético através da implantação de uma tecnologia mais limpa.

Dentre as tecnologias disponíveis e adequadas no mercado, o tratamento térmico por pirólise recebe destaque por reduzir o volume do resíduo em até $90 \%$ de seu peso, além de favorecer o reaproveitamento da matéria-prima em vários segmentos industriais ${ }^{[6,7]}$.

O tratamento por pirólise é definido como a degradação de resíduos por aquecimento em atmosfera deficiente de oxigênio, abaixo do nível estequiométrico de combustão ${ }^{[6]}$. Os processos pirolíticos são endotérmicos, ao contrário do processo de incineração, sendo assim, é necessário o fornecimento de calor ao sistema ${ }^{[7]}$. Ocorrem em temperaturas na faixa de 150 até $1600{ }^{\circ} \mathrm{C}^{[8,9]}$, por meio de conversão catalítica ou não, dependendo do tipo de resíduo a ser tratado e do equipamento utilizado. Os óleos pirolíticos 
Tabela 1. Tipos de resíduos gerados nas plataformas da região da Bacia de Campos ${ }^{[4]}$.

\begin{tabular}{|c|c|c|}
\hline Tipo de resíduo & $\begin{array}{c}\text { Classe } \\
\text { Nbr 10004 }\end{array}$ & Destinação \\
\hline Pilhas e baterias comuns e alcalinas & I & Encaminhadas para o fornecedor \\
\hline Borras oleosas & $\mathrm{I}$ & $\begin{array}{l}\text { Tratadas por Co-processamento em Cimenteira ou encapsulamento em } \\
\text { instalações terrestres da Petrobras }\end{array}$ \\
\hline Lâmpadas fluorescentes & I & Encaminhadas para empresa de reciclagem \\
\hline $\begin{array}{l}\text { Sacarias vazias de produtos químicos } \\
\text { perigosos; }\end{array}$ & I & Encaminhados para empresas de incineração \\
\hline \multicolumn{3}{|l|}{ Resíduos contaminados com óleo; } \\
\hline \multicolumn{3}{|l|}{ Produtos químicos vencidos; } \\
\hline \multicolumn{3}{|l|}{ Resíduos químicos de laboratório; } \\
\hline \multicolumn{3}{|l|}{ Sinalizadores. } \\
\hline Restos de alimentos & IIA & $\begin{array}{l}\text { Triturados a bordo da unidade marítima e lançado ao mar em conformidade } \\
\text { com a Convenção Marpol }\end{array}$ \\
\hline Embalagens metálicas; & IIA & Encaminhadas para empresa de reciclagem \\
\hline \multicolumn{3}{|l|}{ Sucatas de materiais elétricos; } \\
\hline \multicolumn{3}{|l|}{ Sucatas de metais ferrosos } \\
\hline \multicolumn{3}{|l|}{ Carepas de tinta e ferrugem. } \\
\hline Sacaria de madeira papel recicável & IIB & Encaminhadas para empresa de reciclagem \\
\hline \multicolumn{3}{|l|}{ Sucata de metais não ferrosos } \\
\hline \multicolumn{3}{|l|}{ Plásticos recicláveis } \\
\hline \multicolumn{3}{|l|}{ Entulho de obras } \\
\hline \multicolumn{3}{|l|}{ Vidros recicláveis } \\
\hline \multicolumn{3}{|l|}{ Latas de flandre } \\
\hline \multicolumn{3}{|l|}{ Latas de alumínio } \\
\hline \multicolumn{3}{|l|}{ Papelão } \\
\hline \multicolumn{3}{|l|}{ Embalagens plásticas } \\
\hline Sucata plástica & IIB & Encaminhada para empresas de incineração \\
\hline
\end{tabular}

a: Resíduos classe I - Perigoso; Classe IIA - Não - Inertes; Classe IIB - inertes.

produzidos podem ser utilizados como insumo na indústria química; os sólidos apresentam propriedades combustíveis e adsorventes; e os gases podem ser reaproveitados em plantas de geração de energia elétrica, comumente denominadas plantas de co-geração

Segundo Bhaskar et al. (2003) ${ }^{[10]}$, a pirólise é o melhor método para preservar as reservas de petróleo e reduzir o descarte de recursos não degradáveis dispostos no meio ambiente. A utilização do óleo pirolítico proveniente do tratamento de resíduos plásticos como feedstock em refinarias tem apresentado bons resultados em escala piloto e semicomercial e tem representado uma das melhores tecnologias para a reciclagem de plásticos ${ }^{[11,12]}$.

No Brasil, desde 1998, a Petrobras instalou, em São Mateus do Sul no Paraná, uma usina de reprocessamento de xisto e pneus para a produção de óleo e gás combustível. Nesta unidade, uma mistura de $5 \%$ em peso de pedaços de pneus e $95 \%$ em peso de xisto é levada a um reator cilíndrico vertical (retorta), para ser pirolisada a $500{ }^{\circ} \mathrm{C}^{[8]}$. Como produtos, são obtidos óleo pesado e gases de xisto que passam por outro processo de limpeza para produção do óleo leve.
Neste contexto, o desenvolvimento de tecnologias mais limpas para tratamento e destinação final dos resíduos tem sido amplamente discutido no setor industrial. Estas tecnologias devem atender ao conceito de desenvolvimento sustentável, minimizando a geração de emissões dos gases do efeito estufa e com recuperação energética de seus resíduos inevitáveis.

Assim, este trabalho tem como objetivo caracterizar os resíduos sólidos plásticos da indústria offshore, quanto a sua composição polimérica e avaliar a natureza química do óleo gerado durante a pirólise destes produtos.

\section{Parte Experimental}

\section{Coleta e preparo de amostra}

Para o estudo foram selecionados cinco resíduos poliméricos, considerados classe 1 por estarem contaminados com óleos e/ou produtos químicos, da unidade de produção PETROBRAS-40 (P-40), que opera no campo de Marlim Sul na bacia de Campos: embalagens plásticas $(\mathrm{EP})$ vazias de produtos químicos, sacarias vazias de produtos químicos 
(SP), cabos de borracha (CB), cabos de amarração (CA) e correias emborrachadas (CE). Estes resíduos foram triturados manualmente, sem nenhum tratamento prévio.

\section{Caracterização das amostras de resíduos}

Como os resíduos selecionados são provenientes de vários fabricantes, o polímero base de cada resíduo foi estimado considerando o aspecto de seu artefato, a sua densidade em relação água ${ }^{[13,14]}$ e sua composição química obtida através dos ensaios qualitativos de identificação de plásticos, borrachas e fibras desenvolvida por Mano (2000) ${ }^{[14]}$.

\section{Análise termogravimétrica (TG) e térmica diferencial (DTA)}

As análises termogravimétricas (TG) e térmica diferencial (DTA) foram realizadas em balança termogravimétrica SDT 2960, utilizando cápsula de platina, sob as seguintes condições: aquecimento de temperatura ambiente até $1.000{ }^{\circ} \mathrm{C}$ em atmosfera de nitrogênio, fluxo de gás de $100 \mathrm{~mL} / \mathrm{min}$ e taxa de aquecimento de $20^{\circ} \mathrm{C} / \mathrm{min}$. A avaliação termogravimétrica das amostras seguiu as diretrizes estabelecidas nas normas técnicas ASTM E-1868-04 ${ }^{[15]}$ e ASTM E-1131-03 ${ }^{[16]}$.

\section{Pirólise dos resíduos}

As amostras de resíduos foram submetidas à técnica de pirólise sob atmosfera de nitrogênio. A unidade de pirólise (Figura 1) é constituída basicamente de forno vertical e de um reator de aço. Pela extremidade superior do reator, é adaptada a vávula para entrada do gás nitrogênio (fluxo de $35 \mathrm{~mL} / \mathrm{min}$ ) e na extremidade inferior é acoplado um condensador de vidro imerso em um banho de gelo para recolhimento do líquido pirolítico. O sistema opera com base nas normas do Standart Test Procedure estabelecida no ASTM 3907-92 $2^{[17]}$.

A pirólise ocorreu na temperatura de $450{ }^{\circ} \mathrm{C}$, por 15 minutos, e os líquidos pirolíticos foram caracterizados por espectrofotometria de infravermelho com transformada de Fourier (FTIR) e cromatografia em fase gasosa acoplada à espectrometria de massas (CG/EM). A eficiência da pirólise foi avaliada considerando a quantidade mássica percentual de produtos líquidos, gasosos e sólidos gerados.

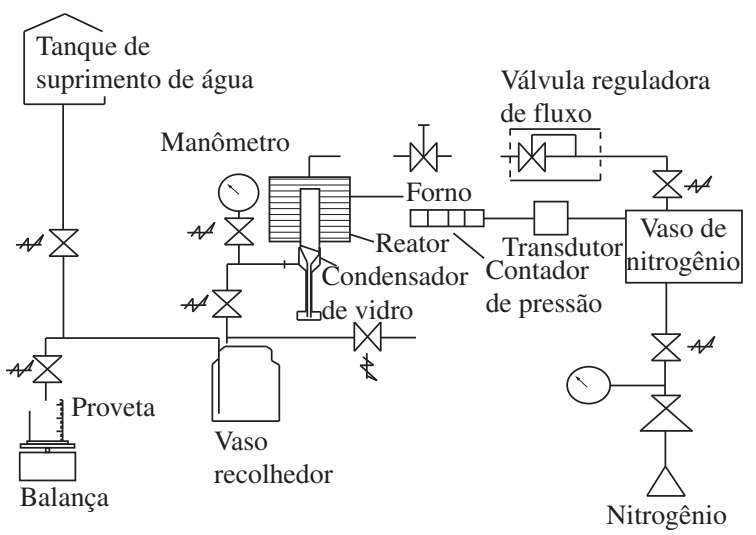

Figura 1. Fluxograma resumido da unidade de pirólise.
As análises por FTIR foram realizadas em filmes líquidos em células de $\mathrm{KBr}$ utilizando o espectrofotômetro Spectrum One da Perkin Elmer com as seguintes condições: resolução $4 \mathrm{~cm}^{-1}$, região espectral 4000 a $400 \mathrm{~cm}^{-1}$ e 40 varreduras. As análises por $\mathrm{CG} / \mathrm{EM}$ foram realizadas em um equipamento Varian 1200 L, utilizando uma coluna capilar DB-5 $(30 \mathrm{~m} \times 0,25 \mathrm{~mm} \times 0,25 \mu \mathrm{m})$ com a fase estacionária composta por $5 \%$ de fenil e $95 \%$ de dimetilpolisiloxano; gás de arraste hélio (pressão de $54 \mathrm{kPa}$ e vazão de $1 \mathrm{~mL} \mathrm{~min}{ }^{-1}$, volume de injeção de $1 \mu \mathrm{L}$ e modo split 1:20). Condições cromatográficas: $250^{\circ} \mathrm{C}$ a temperatura da interface, gradiente de temperatura da coluna: $40{ }^{\circ} \mathrm{C}$ (2 minutos); $10{ }^{\circ} \mathrm{C} \mathrm{min}{ }^{-1}$ até $200{ }^{\circ} \mathrm{C}$ (0 minuto); $20{ }^{\circ} \mathrm{C} \mathrm{min}{ }^{-1}$ até $300{ }^{\circ} \mathrm{C}$ (10 minutos). A identificação dos compostos foi efetuada comparando-se os espectros de massas obtidos com a biblioteca NIST 05 Mass Spectral Library comercializada pela Varian e integrante do equipamento.

\section{Resultados e Discussões}

A Tabela 2 apresenta a caracterização prévia dos resíduos sólidos offshore selecionados, considerando o aspecto visual dos resíduos, as informações fornecidas pelos fabricantes e os ensaios de densidade do polímero, utilizando como referência a densidade da água ${ }^{[13]}$.

Os resultados da densidade em água indicaram que as amostras de correia emborrachada (CE), cabo de borracha (CB) e cabo de amarração (CA) foram identificadas como mais densas que água e, portanto não apresentam como principal constituinte poliolefinas. A única amostra que foi identificada como menos densa que a água foi a amostra de embalagem plástica (EP), corroborando com a estimativa de ser um artefato de PEAD.

A caracterização química das amostras poliméricas de resíduo offshore foi realizada com base na metodologia desenvolvida por Mano (2000) ${ }^{[14]}$. As amostras foram submetidas aos ensaios para a verificação de presença de halogênios, nitrogênios, grupamento nitrílico e anéis aromáticos.

O ensaio de Beilstein permite a identificação de halogênios através da verificação de lampejos azuis e/ou verdes na chama do bico de Bunsen. Os resíduos de embalagem plástica (EP) e de sacaria de produtos químicos (SP) não foram testados já que foram previamente definidos como sendo poliolefinas pelo ensaio de densidade e pelos dados do fabricante respectivamente. O resultado do ensaio de Beilstein, para as demais amostras, confirmou a caracterização preliminar, uma vez que não se verificou lampejos coloridos, indicando que o polímero-base destes artefatos não são halogenados (Tabela 3).

A identificação de nitrogênio em polímeros é verificada pelo desprendimento de vapores de amônia durante a calcinação da amostra com óxido de cal. O óxido de cal retém os vapores ácidos e os vapores básicos e neutros são 
Tabela 2. Caracterização prévia das amostras.

\begin{tabular}{cccc}
\hline Resíduos & Aspecto visual & $\begin{array}{c}\text { Densidade em relação à } \\
\text { densidade da água }\end{array}$ & $\begin{array}{c}\text { Estimativa do principal } \\
\text { constituinte }\end{array}$ \\
\hline Embalagem plástica (EP) & Branco, opaco, superfície fosca, duro e & Menos denso & PEAD \\
resistente & Mais denso & Mistura de borrachas \\
Correia emborrachada (CE) & Preto, textura compacta, rígido & Mais denso & Mistura de borrachas \\
Cabo de borracha (CB) & Preto, textura compacta, rígido & Mais denso & Poliéster ou poliamida \\
Cabo de amarração (CA) & Fios brancos, opacos e resistentes & Não testada & PP \\
Sacarias de produtos químicos (SP) & Fibra branca, opaca, flexível e resistente & \\
\hline
\end{tabular}

Tabela 3. Caracterização das amostras por caracterização química.

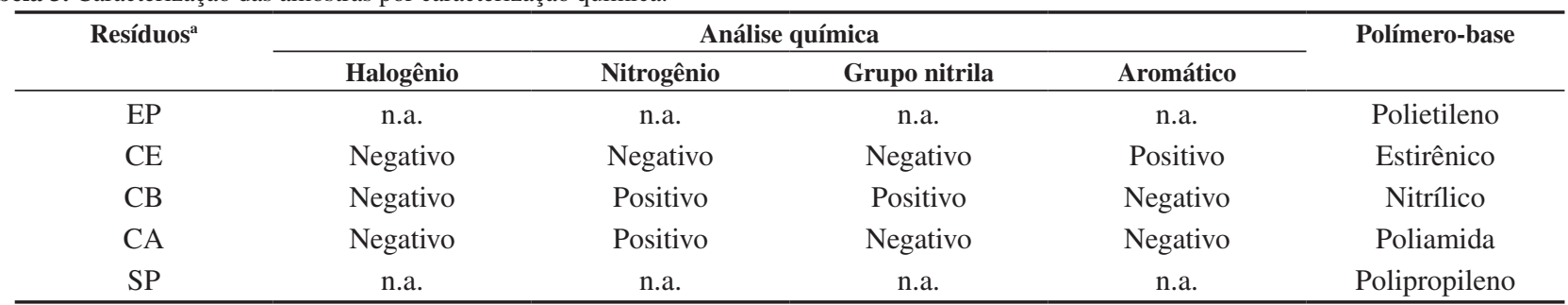

n.a.: não avaliado (poliolefinas); aembalagem plástica (EP), correia emborrachada (CE), cabo de borracha (CB), cabo de amarração (CA), sacarias de produtos químicos (SP).

deslocados até a boca do tubo de ensaio, alterando a coloração do papel de tornassol de rosa para azul.

Este ensaio foi positivo para as amostras cabo de borracha (CB) e cabo de amarração (CA), caracterizando que o polímero base destas amostras é constituído por átomos de nitrogênio trivalente. De acordo com este resultado, sugere-se que o cabo de amarração (CA) é uma poliamida comumente utilizada na fabricação de fibras e o cabo de borracha (CB) é um artefato constituído de borracha nitrogenada (Tabela 3).

A identificação de polímero nitrílico é observada na pirólise da amostra pelo desprendimento de vapores de ácido cianídrico que ao reagir com acetato cúprico/benzidina forma o nitroprussiato de cobre. Como resultado, observouse a formação de coloração azul na pirólise da amostras de cabo de borracha (CB), que caracteriza a possível presença de polímero nitrílico (Tabela 3 ).

A verificação de presença de anel aromático, alquilado ou arilado em moléculas orgânicas é feita por meio de reações de substituição eletrofílica em anéis aromáticos. $O$ ataque de ácido sulfúrico ao anel aromático forma um composto sulfonado que possui coloração alaranjada. Assim, a mudança de cor nos fragmentos de amostra comprova a existência de anel aromático na composição do polímero. Este ensaio foi realizado nas amostras de correia emborrachada (CE), cabo de borracha $(\mathrm{CB})$ e cabo de amarração $(\mathrm{CA})$. A presença de anel aromático foi verificada somente na amostra de correia emborrachada - CE (Tabela 3).

Neste estudo, o TG e o DTA foram empregados para verificação das alterações que o aquecimento pode provocar na massa das amostras de resíduos offshore, a fim de poder estabelecer a faixa de temperatura na qual o material inicia o processo de decomposição $0^{[18]}$.

A curva de TG da amostra de resíduo de embalagem plástica - EP (Figura 2a) apresenta perda de massa entre as temperaturas de 240 e $500{ }^{\circ} \mathrm{C}$, na ordem de $99,4 \%$, com observação de um resíduo após $1000{ }^{\circ} \mathrm{C}$ de cerca de $0,6 \%$. A curva de DTA mostra dois tipos de transformações endotérmicas: aproximadamente 150 e $500{ }^{\circ} \mathrm{C}$.

Ao comparar as curvas de TG e DTA (Figura 2a), observase uma perda de massa na segunda região, o que sugere a degradação do material. A primeira transformação refere-se à fusão do material que se encontra na faixa de temperatura da Tm do HDPE ${ }^{[19,20]}$.

A curva de TG da amostra correia emborrachada - CE (Figura 2b) apresenta perdas de massas entre a temperatura ambiente e $550{ }^{\circ} \mathrm{C}$ na ordem de $56 \%$, entre 550 e $1000{ }^{\circ} \mathrm{C}$ em torno de $5 \%$ e um resíduo após $1000{ }^{\circ} \mathrm{C}$ de $39 \%$. De acordo com as curvas desta amostra, a ocorrência de duas etapas de degradação pode indicar que esta amostra é constituída de material multifásico ou um copolímero. O percentual de resíduo elevado pode ser oriundo da adição de negro de fumo, normalmente utilizado na composição de borrachas de coloração preta.

$\mathrm{Na}$ curva de TG da amostra de cabo de borracha - CB (Figura 2c), são verificadas perdas de massas entre as temperaturas de 180 a $510{ }^{\circ} \mathrm{C}$ na ordem de $56 \%$, entre as temperaturas de 700 e $1000{ }^{\circ} \mathrm{C}$ de $3 \%$ e um resíduo após $1000{ }^{\circ} \mathrm{C}$ de $40 \%$. O percentual de resíduo elevado nesta amostra também pode ser proveniente da presença de negro de fumo.

A curva de DTA (Figura 2c) apresenta duas transformações endotérmicas: a primeira em torno de $350{ }^{\circ} \mathrm{C}$ e a segunda iniciando-se em $500{ }^{\circ} \mathrm{C}$, região onde há a perda de massa do material, sugerindo a degradação do mesmo. O pico na temperatura de $378{ }^{\circ} \mathrm{C}$ na curva de DTA não corresponde a um sinal exotérmico.

A curva de TG da amostra de cabo de amarração - CA (Figura 2e) apresenta transformações endodérmicas com perdas de massas entre a temperatura ambiente e $100{ }^{\circ} \mathrm{C}$ na ordem de $5 \%$, entre 125 e $420{ }^{\circ} \mathrm{C}$ na ordem de $71 \%$, entre 


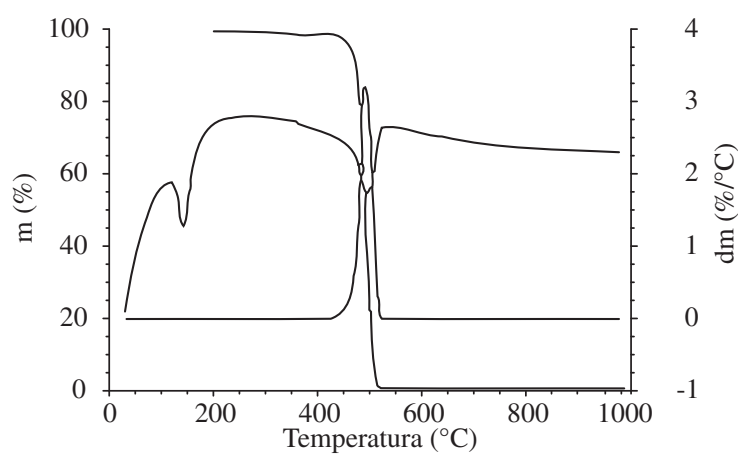

(a)

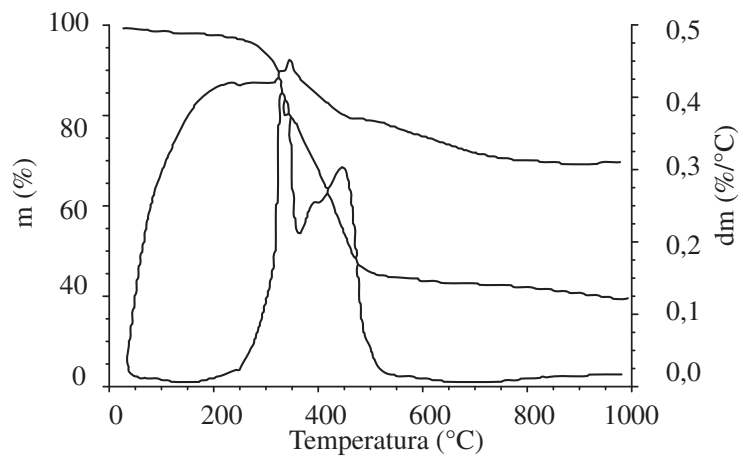

(b)

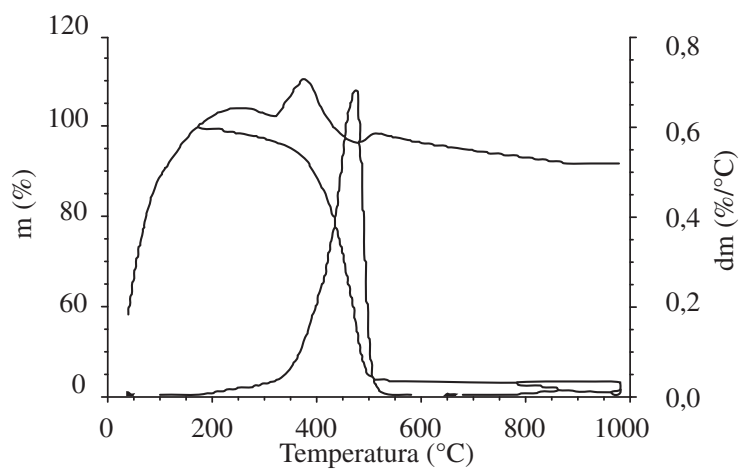

(c)

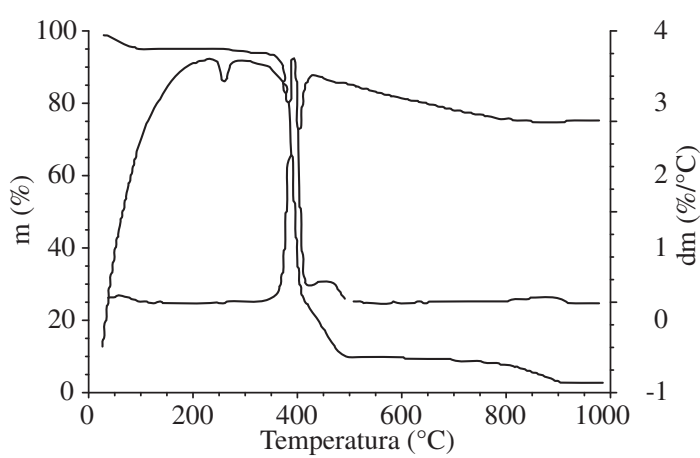

(d)

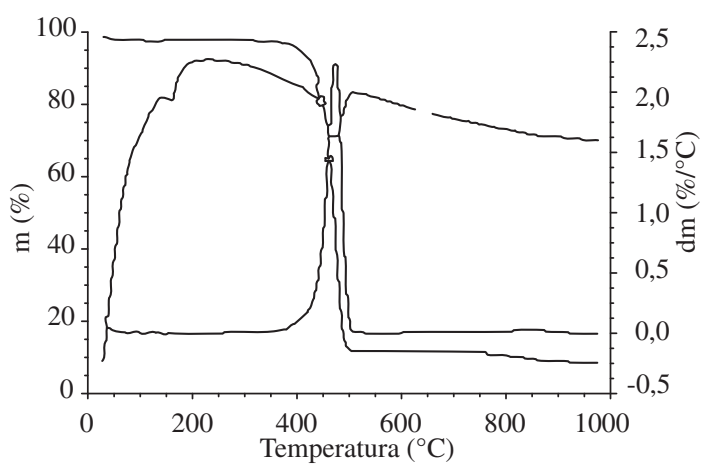

(e)

Figura 2. TGA/DT das amostras de resíduos offshore: a) embalagem plástica; b) correia emborrachada; c) cabo de borracha; d) cabo de amarração; e) sacaria de produtos químicos. (curvas de TG em verde, a DTG em azul e as DTA em vermelho).

420 e $510{ }^{\circ} \mathrm{C}$ na ordem de $14 \%$, entre 650 e $910{ }^{\circ} \mathrm{C}$ em torno de $7 \%$ e um resíduo após $1000{ }^{\circ} \mathrm{C}$ de $3 \%$. A transformação endotérmica em torno de $250^{\circ} \mathrm{C}$ refere-se à fusão do material e coincide com a fusão verificada para as poliamidas utilizadas para a fiação ${ }^{[21]}$.

A primeira perda de massa refere-se à perda de água, que possuem estrutura semicristalina, polar e apresentam alto grau de higroscopia.

A curva de TG da amostra de resíduo de sacarias de produtos químicos - SP (Figura 2d) apresenta transformações endodérmicas com perdas de massas entre as temperaturas de 300 e $550{ }^{\circ} \mathrm{C}$ na ordem de $88 \%$, entre 650 e $880{ }^{\circ} \mathrm{C}$ na ordem de $3 \%$ e um resíduo após $1000{ }^{\circ} \mathrm{C}$ de $9 \%$.

A curva de DTA apresenta duas transformações endotérmicas: a primeira iniciando-se em torno de $150{ }^{\circ} \mathrm{C}$, referente a fusão do material, e a segunda iniciando-se em $470{ }^{\circ} \mathrm{C}$, que ocorre na região onde há a perda de massa do material, indicando a degradação do mesmo.

A Tabela 4 apresenta o rendimento dos produtos de pirólise (balanço de massas) das amostras picotadas manualmente e pirolisadas isoladamente na temperatura de $450{ }^{\circ} \mathrm{C}$. De acordo com esses resultados, observa-se que os maiores rendimentos de óleo pirolítico foram obtidos para as amostras de correia emborrachada - CE (37\%), cabo de borracha - CB (41\%) e sacaria de produtos químicos - SP (38\%).

Os resultados de pirólise das amostras foram compatíveis com o teste de TGA, excluindo-se o resíduo de cabo de amarração (CA), que apresentou uma perda de massa (28\%), bem abaixo do esperado pela análise termogravimétrica $\left(71 \%\right.$ entre 125 e $420{ }^{\circ} \mathrm{C}$ ). Este resultado pode ser devido 
à granulometria do material, uma vez que foi picotado manualmente.

As principais bandas de absorção no infravermelho e os principais produtos sugeridos pelos espectros de massa da biblioteca NITS 05 Mass Spectral Library dos óleos pirolíticos provenientes das amostras de resíduos estão apresentados na Tabela 5.

A análise do espectro de FTIR do líquido pirolítico da embalagem plástica (EP) mostrou a presença de bandas de deformação axial assimétrico e simétrico do grupamento metileno em 2922 e $2851 \mathrm{~cm}^{-1}$, respectivamente, e deformação simétrica fora do plano de metileno em $909 \mathrm{~cm}^{-1}$, características de alcanos de cadeia longa. Observa-se também, bandas características de vibração axial de $\mathrm{C}=\mathrm{C}$ de alcenos em torno de $1640 \mathrm{~cm}^{-1[22]}$.

Tabela 4. Balanço de massas (\%) da pirólise dos resíduos sólidos offshore.

\begin{tabular}{cccc}
\hline Resíduo $^{\mathbf{a}}$ & \multicolumn{3}{c}{ Balanço de massas (\% peso) } \\
\cline { 2 - 4 } & Gás & Óleo & Sólido \\
\hline $\mathrm{CA}$ & 16 & 12 & 72 \\
$\mathrm{CE}$ & 10 & 37 & 53 \\
$\mathrm{CB}$ & 14 & 41 & 45 \\
$\mathrm{EP}$ & 7 & 12 & 81 \\
$\mathrm{SP}$ & 10 & 38 & 52 \\
\hline
\end{tabular}

${ }^{a}$ Cabo de amarração (CA); correia emborrachada (CE); cabo de borracha $(\mathrm{CB})$; embalagem plástica (EP); e sacaria de produtos químicos (SP).
Segundo Oliveira (2006) ${ }^{[5]}$ e Carneiro (2007) ${ }^{[23]}$, a pirólise de polietieno fornece altas concentrações de alcanos, alcenos e alcadienos. A análise de CG/EM de produtos de pirólise de polietileno no trabalho de Bockhorn (1998) ${ }^{[24]}$ também revelou altas quantidades de n-alcanos e n-alcenos, compostos característicos do óleo diesel.

$\mathrm{O}$ espectro de FTIR do líquido pirolítico da amostra correia emborrachada (CE) apresentou bandas características de: 1) alcanos (deformação axial assimétrica e simétrica de $\mathrm{CH}_{2}$ em 2924 e $2855 \mathrm{~cm}^{-1}$ ); 2) aromáticos (deformação axial $\mathrm{C}=\mathrm{C}$ do anel em 1454 e $1604 \mathrm{~cm}^{-1}$ e deformação axial $\mathrm{C}=\mathrm{O}$ de ácidos aril conjugados em $1698 \mathrm{~cm}^{-1}$ ); e 3) ácidos (deformação axial de O-H em $3300 \mathrm{~cm}^{-1}$ e deformação axial C-O do ácido em $1271 \mathrm{~cm}^{-1}$ ). Além desses, também foi observada uma banda característica de poliestireno em $1493 \mathrm{~cm}^{-1}$, coerente com a estrutura do polímero-base (borracha estirênica) ${ }^{[22]}$

A análise quantitativa do CG/EM indicou que o ácido benzóico foi a principal substância (rendimento em torno de 60\%) formada na pirólise da CE. A formação de estireno também foi constatada, mas o seu rendimento ficou abaixo de $10 \%$. Este fato não esperado, sugere que o teor de oxigênio do nitrogênio comercial, esteja acima do ideal para as condições de pirólise.

$\mathrm{O}$ espectro de FTIR do cabo de borracha (CB) mostra bandas de deformação axial assimétrica e simétrica do grupamento metileno nas faixas de freqüências $2927 \mathrm{~cm}^{-1}$ e $2857 \mathrm{~cm}^{-1}$ respectivamente, características de parafinas.

Tabela 5. Principais absorções do FTIR, classe de compostos e principais produtos dos líquidos pirolíticos das amostras.

\begin{tabular}{|c|c|c|c|}
\hline Resíduo & Principais bandas de absorção no FTIR & $\begin{array}{l}\text { Presença dos principais } \\
\text { grupos funcionais }\end{array}$ & Principais produtos $^{\mathrm{a}}$ \\
\hline $\begin{array}{l}\text { Embalagem plástica } \\
\text { (EB) }\end{array}$ & $\begin{array}{l}\text { a) def. axial assimétrica e simétrica } \mathrm{CH}_{2} \text {, } \\
2922 \text { e } 2851 \mathrm{~cm}^{-1} \text {; b) def. simétrica fora do } \\
\text { plano } \mathrm{CH}_{2}, 909 \mathrm{~cm}^{-1} \text {; e c) vibração axial } \mathrm{C}=\mathrm{C} \text {, } \\
1640 \mathrm{~cm}^{-1}\end{array}$ & Parafínicos e olefínicos & $\begin{array}{l}\text { 5-eicoseno; } \\
\text { 5-octadeceno; } \\
\text { 3-eicoseno; } \\
\text { 9-eicoseno }\end{array}$ \\
\hline $\begin{array}{l}\text { Correia emborrachada } \\
\text { (CE) }\end{array}$ & $\begin{array}{l}\text { a) def. axial assimétrica e simétrica } \mathrm{CH}_{2}, 2924 \\
\text { e } 2855 \mathrm{~cm}^{-1} \text {; b) def. axial } \mathrm{C}=\mathrm{C}, 1454 \mathrm{~cm}^{-1} \text { e def. } \\
\text { axial } \mathrm{C}=\mathrm{O}, 1698 \mathrm{~cm}^{-1} \text {; e c) def. } \mathrm{C}-\mathrm{O}, 1271 \mathrm{~cm}^{-1}\end{array}$ & Aromáticos e carboxílicos & $\begin{array}{l}\text { ácido benzóico; } \\
\text { estireno }\end{array}$ \\
\hline $\begin{array}{l}\text { Cabo de borracha } \\
\text { (CB) }\end{array}$ & $\begin{array}{l}\text { a) def. axial assimétrica e simétrica } \mathrm{CH}_{2} \text {, } \\
2927 \text { e } 2857 \mathrm{~cm}^{-1} \text {; e b) def. axial de } \mathrm{C} \equiv \mathrm{N} \text {, } \\
2237 \mathrm{~cm}^{-1}\end{array}$ & $\begin{array}{l}\text { Nitrílicos e grupos } \\
\text { metilênicos }\end{array}$ & $\begin{array}{l}\text { Ttetradecanitrila; } \\
\text { Eeicosanonitrila; } \\
\text { nonadecanitrila; } \\
\text { hexadecanitrila; } \\
\text { heptadecanitrila; }\end{array}$ \\
\hline $\begin{array}{l}\text { Cabo de amarração } \\
\text { (CA) }\end{array}$ & $\begin{array}{l}\text { a) def. axial de } \mathrm{C}=\mathrm{O}, 1645 \mathrm{~cm}^{-1} \text {; b) def. axial } \\
\text { e angular de } \mathrm{N}-\mathrm{H}, 3272 \text { e } 1557 \mathrm{~cm}^{-1} \text {; c) def. } \\
\text { axial assimétrica e simétrica } \mathrm{CH}_{2}, 2930 \text { e } \\
2858 \mathrm{~cm}^{-1}\end{array}$ & Nitrogenados e oxigenados & $\begin{array}{l}\text { 8-aminoquinaldina; } \\
\text { 4-metil-8-aminoquinaldina; } \\
\text { acetamida }\end{array}$ \\
\hline $\begin{array}{l}\text { Sacaria de produtos } \\
\text { químicos }(\mathrm{SP})\end{array}$ & $\begin{array}{l}\text { a) def. axial assimétrica e simétrica } \mathrm{CH} \text {, } \\
2956 \text { e } 2870 \mathrm{~cm}^{-1} ; \text { b) def. axial assimétrica } \\
\mathrm{C}-\mathrm{H}, 2916 \mathrm{~cm}^{-1} \text {; c) def. angular simétrica } \\
\mathrm{C}-\mathrm{H}, 1458 \mathrm{~cm}^{-1}\end{array}$ & Parafínicos e olefínicos & $\begin{array}{l}\text { 3-eicoseno; } \\
\text { 5-octadeceno; } \\
\text { 9-eicoseno; } \\
\text { 11-tricoseno; } \\
\text { 1-tricoseno; } \\
\text { ciclooctasano }\end{array}$ \\
\hline
\end{tabular}

${ }^{a}$ Conforme sugestão fornecida pela biblioteca NITS 05 Mass Spectral Library do CG/EM, com probabilidade superior a $70 \%$. 
Observa-se também uma banda de formação axial da ligação $\mathrm{C} \equiv \mathrm{N}$ na freqüência de $2237 \mathrm{~cm}^{-1}$, característica de substâncias nitrílicas de cadeia saturada longa ${ }^{[22]}$. Este resultado é coerente com a estrutura do polímero-base, borracha nitrílica.

$\mathrm{O}$ espectro de FTIR da amostra cabo de amarração (CB) apresenta bandas de deformação axial de grupo carbonila insaturada $\left(1645 \mathrm{~cm}^{-1}\right)$ e deformações axial e angular de $\mathrm{N}-\mathrm{H}$ características de amida nas freqüências 3272 e $1557 \mathrm{~cm}^{-1}$, respectivamente. Além das bandas de deformação axial assimétrica e simétrica do grupamento $\mathrm{CH}_{2}^{[22]}$. A existência de compostos contendo grupo amida no líquido pirolítico é coerente com a estrutura do polímero base (uma poliamida), conforme confirmado pelos espectros de massa dos subprodutos do óleo pirólitco.

São observadas no espectro de FTIR da amostra de sacaria de produtos químicos (SP) bandas características de alcanos em: 1) deformação axial assimétrica e simétrica de $\mathrm{C}-\mathrm{H}$ do grupamento metila nas frequiências 2956 e $2870 \mathrm{~cm}^{-1}$; 2) deformação axial assimétrica de grupamento metileno na freqüência $2916 \mathrm{~cm}^{-1}$; e 3) deformação angular simétrica $\mathrm{C}-\mathrm{H}$ do grupamento metila na freqüência $1458 \mathrm{~cm}^{-1}$. Além destas bandas, também foram encontradas bandas de deformação axial $\mathrm{C}=\mathrm{C}$ e deformação angular fora do plano de $=\mathrm{CH}_{2}$ nas frequiências 1650 e $887 \mathrm{~cm}^{-1}$ respectivamente, características de alcenos $^{[22]}$.

Os espectros de massa indicaram por meio da biblioteca NIST 05 Mass Spectral Library produtos que confirmam a formação de compostos parafínicos e olefinicos, como sugerido pelo FTIR. Este resultado também foi verificado por Bockhorn (1998) ${ }^{[24]}$, onde a análise de CG/EM indicou que $85 \%$ de olefinas foram obtidas na pirólise de polipropileno.

\section{Conclusão}

A pirólise a $450{ }^{\circ} \mathrm{C}$ de resíduos sólidos offshore reduz o volume de resíduo gerado demonstrando ser uma das soluções para a questão de destinação final de resíduos no Brasil. Além disso, a pirólise de embalagens plásticas (EP) e de sacarias de produtos químicos (SP) forneceu um óleo pirolítico composto basicamente de parafinas e olefinas de peso molecular fornecendo uma possível reutilização para estes resíduos com óleo combustível.

\section{Agradecimentos}

Os autores agradecem a Petrobras pela doação da Unidade de Pirólise e dos resíduos offshore. À Faperj, CNPq, Capes pelo aporte financeiro e ao Prof. Dr. Carlos Alberto Riehl da Silva do DQA do Instituto de Química, pelas análises de CG/EM. Lucianna Lopes Cabral agradece à Capes a bolsa de estudos.

\section{Referências Bibliográficas}

1. MINISTÉRIO NACIONAL DO MEIO AMBIENTE. CONSELHO NACIONAL DO MEIO AMBIENTE CONAMA - "Resolução $n$. 001, de 23 de janeiro de 1986. Dispõe sobre procedimentos relativos a estudo de impacto ambiental", Brasília (1986).

2. PETROBRAS - "Relatório de Controle Ambiental, Bacia de Santos, Bloco BM-S-10", NEXP Petrobras, Rio de Janeiro - RJ (2004).

3. ASSOCIAÇÃO BRASILEIRA DE NORMAS TÉCNICAS - ABNT - "NBR 1004. Resíduos sólidos classificação", Rio de Janeiro (2004).

4. Moni, R.C. - "O sistema de gerenciamento de resíduos da Bacia de Campos e sua relação com os sistemas de gestão ambiental existentes: uma proposta de gestão integrada", Dissertação de Mestrado, Universidade Federal Fluminense, Niterói, Rio de Janeiro, Brasil (2003).

5. Oliveira, M. L. - "Caracterização e pirólise dos resíduos da Bacia de Campos: análise dos resíduos da P-40", Dissertação de Mestrado, Universidade do Estado do Rio de Janeiro, Rio de Janeiro, Brasil (2006).

6. Ojolo, S. J.; Bamgboye, A. I.; Aiyedun, P. O. \& Ogunyemi, A. P. - "Pyrolysis of shredded plastic waste". Disponível em: <http://www.isis.fastmail.usf. edu/ibl/manutech\%20papers/ojolo\%20\%20sunday. pdf $>$.

7. Aires, R. D. et al. - "Pirólise", in: III Fórum de Estudos Contábeis, Rio Claro - SP (2003).

8. Andrietta, A. J. - "Pneus e meio ambiente: um grande problema requer uma grande solução", (2002). Disponível em: <http://www.reciclarepreciso.hpg. ig.com.br/recipneus.htm>.

9. Menezes, R. - "Destruição Térmica de Resíduos Sólidos Urbanos e Especiais: indicadores operacionais", Curso ABES - CEF (1999). Disponível em: <www. kompac.com.br>.

10. Bhaskar, T.; Uddin, M. D. A.; Murai, K.; Kaneko, J.; Hamano, K.; Kusaba, T.; Muto, A. \& Sakata, Y. - J. Anal. Appl. Pyrolysis. 70, p.579 (2003).

11. Kaminsky, W.; Predel, M. \& Sadiki, A. - Polym. Degrad. Stab. 85, p.1045 (2004).

12. Demirbas, A. - J. Anal. Appl. Pyrolysis. 72, p.97 (2004).

13. Vilhena, A. (Coord.) - "Lixo Municipal: manual de gerenciamento integrado", IPT/CEMPRE, São Paulo - SP (2000).

14. Mano, E. B. \& Mendes, L. C. - "Identificação de plásticos, borrachas e fibra", Edgard Blücher, São Paulo - SP (2000).

15. AMERICAN SOCIETY FOR TESTING AND MATERIALS - ASTM. - "ASTM 1868, Standard Test 
Method for Loss-On-Drying by Thermogravimetry", American Standart Methods (2004).

16. AMERICAN SOCIETY FOR TESTING AND MATERIALS - ASTM. - "ASTM 1131, Standard Test Method for Compositional Analysis by Thermogravimetry", American Standart Methods (2003).

17. AMERICAN SOCIETY FOR TESTING AND MATERIALS - ASTM. - "ASTM 3907, Standard Method for Testing Fluid Catalytic Cracking (FCC)", American Standart Methods (1992).

18. Lucas, E. F.; Soares, B. G. \& Monteiro, E. E. C. "Caracterização de polímeros - determinação de peso molecular e análise térmica", E-papers, Rio de Janeiro - RJ (2001).

19. Wu, Y.; Isarov, A.V. \& O'Conell, C. - Thermochim. Acta. 340-341, p.205 (1999).
20. Kim, S.; Jang, E. S.; Shin, D. H. \& Lee, K. H. - Polym. Degrad Stab. 85, p.799 (2004).

21. Mano, E. B. \& Mendes, L. C. - "Introdução a polímeros", Edgard Blücher, São Paulo - SP (1999).

22. Silverstein, R. M.; Bassler, G. C. \& Morril, T. C. "Identificação espectofotométrica de compostos orgânicos", Guanabara Koogan, Rio de Janeiro - RJ (1994).

23. Carneiro, D. S. - "Co-pirólise de resíduos de polietileno com gás-óleo da Bacia de Campos", Dissertação de Mestrado, Universidade do Estado do Rio de Janeiro, Rio de Janeiro, Brasil (2007).

24. Bockhorn, H. et al. - Chem. Eng. Sc. 54, p.3043 (1998).

Enviado: $19 / 01 / 09$

Reenviado: $21 / 08 / 09$

Aceito: $27 / 08 / 09$ 